Journal Homepage:

http://perlinguam.journals.ac.za
Per Linguam
A Journal for Language Learning

Tydskrif vir Taalaanleer

\title{
SELECTING LITERATURE FOR BEGINNER READERS IN SOUTH AFRICA
}

Liesel Hibbert \& Marius Crous

Nelson Mandela Metropolitan University

This article explores complexities of choosing appropriate reading material which may provide maximum engagement for beginner readers in Southern Africa, with the aim of instilling a lifelong love of reading. The article presents a case in favour of literary criteria as base line for choices of reading material for beginner readers. Furthermore, the article outlines general characteristics of reading material for beginner readers, as well as specific criteria to be considered in the Southern African context, taking into account the linguistic diversity which exists in formal education and the vast literacy backlog in the region. Furthermore, it is argued that translated children's stories should ideally be adapted rather than literally translated, in order to meet the requirements of what is universally regarded as good children's literature for beginner readers. A culture of reading can only be instilled by adhering to the following criteria, i.e. ensuring affective engagement, maximum meaning-making potential, delight, the engagement of the imagination for the purposes of developing the creative mind, and strong identification with the material for the purposes of developing a sense of agency.

\section{INTRODUCTION}

The purpose of this article is to highlight several dilemmas when creating or selecting appropriate reading material for beginner readers. These dilemmas are, amongst others, balancing literariness with linguistically appropriate reading material. Secondly, a dilemma exists between cultural and affective engagement versus the economic considerations of publishers. Thirdly, the South African multilingual classroom body has to be taken into account while the proficiency of English has to be promoted among all learners. Fourthly, the challenge of translation for saleability, on the one hand, and literariness on the other hand, needs to be investigated. We argue that cultural and linguistic sensitivity to diversity promotes integrity in the publishing industry and enhances motivation amongst readers. Martinez and McGee (2000), as well as Brown (1999), underline the importance of authentic literature as essential component of reading instruction. Our argument further emphasises the importance of considering all these factors when providing reading material for the beginner reader in linguistically and culturally diverse educational spaces, be they formal and structured or unstructured. Ultimately the aim is 
to instil a sense of personal agency amongst beginner readers, which may lay the foundation for lifelong reading.

\section{LITERACY, MULTILINGUAL CITIZENSHIP AND THE PUBLISHING INDUSTRY}

All eleven of the official languages in South Africa ought to appear increasingly in children's books and school readers, due to increasing support for mother tongue education in the Foundation Phase (Grades 1 - 4) within the National Department of Education, according to the new CAPS curriculum. In the event of publishers commissioning translations of children's books, a choice of method of translation needs to be made. The marketability of South African literature in English to be marketed in Africa and abroad is often an additional incentive for local publishers to commission such work. Current writers of children's literature in South Africa, if engaged full time in a mode which is dependent on getting published, have, through necessity, cast their net towards the international children's book market to make their endeavours financially viable. The best prize-winning internationally-known South African children's book authors and illustrators (who have asked to remain anonymous) have turned away from the local market and have made a name for themselves in children's world literature which has been translated from English into a multitude of European languages. Their books have found their way into prescribed school-based reading material in Europe, but not in South Africa.

The cost of producing eleven times as much educational material as before, as well as the task of locating African language writers and translators, has become overwhelming to local publishers. Some publishers made the decision to keep the original illustrations which were created to match and compliment the original text and simply reprint the books in any number of different languages. Haidee Kruger (2010:122) gives examples of such texts: The Day when Gogo went voting/ Die dag toe Gogo gaan stem het by Sisulu; Nicki Daly's Lekker verjaar, Jamela / Happy birthday, Jamela and Where's Jamela? / Waar is Jamela?

South African multilingual society does not seem to lend itself to the easy option open to translators in straight-forward, economically large middle-class bilingual countries such as Belgium or Canada, where the socio-economic status of the language users is fairly similar; where the languages have equal official status; and both language communities are equally literate, as well as predominantly economically secure. Megrab (1998: 69) regards 'societal, institutional and economic micro-dimensions' as major influences on the format and the construction of the text in translated form.

In South Africa, the majority of people still live below the breadline (Burgess, 2003), which makes the purchasing of books a luxury. It is therefore important that schools provide proper reading material for young learners. In the next section an argument is presented in favour of literary criteria as base line for the production, selection and /or translation of children's literature for beginner readers. Secondly, it outlines additional considerations for the South African context, for the teaching of reading in formal educational settings. 


\section{THE ROLE OF TRANSLATION}

This section outlines the factors impacting on the production of appropriate and potentially empowering literature for children in multilingual countries such as South Africa, where translation is often seen as 'the answer' by publishers. The crisis stems from publishers hedging their bets against losses in the education policy crisis since the introduction of the new curricula, OBE and consequent revisions of OBE. Curriculum revisions have introduced insecurity among publishing houses and their future relationship with their educational markets, which has caused the on and off freezing of school book publishing since 1995 .

In contemporary discourse theory it is suggested that changing the word is changing the world, not only with reference to translation, but also to practices of rephrasing, rewriting and/or reshaping text. Furthermore, 'cultural, aesthetic, national, ideological, pedagogical and economic issues are all at work in shaping translations' (Stan, 2004: 31). If all languages are seen as context-based and metaphorical (Lakoff \& Johnson, 1980), and as culturally and socially determined and determining (Fairclough, 1989; Halliday, 1996), it follows that it is problematic to translate texts literally, as well as to transport same-language texts into diverse cultural communities, because each language has its own sound system and socially-embedded practices, range of signifiers, metaphorical bases, connotations and ways of presenting content in different genres. As a result, the translator often has to opt for non-equivalence at the level of both the word and meaning. Baker (2011: 23-46) suggests several strategies which the translator could use in order to deal with the various types of non-equivalence. These strategies will be explored in detail in due course.

The dilemma is which translation method would be the best to create reading material for beginner readers in South Africa. The translation also depends on whether the publisher should adhere to literariness or aim to produce cost-effective school reading material. Which translation method would one choose in order to ensure that texts retain these essential linguistic elements but ensure maximum engagement at the reception end when presented to beginner readers? In her analysis of the translation of children's books, Kruger (2010: 123) follows the descriptive approach pioneered by Toury. According to this approach, the 'function of the translated text within the recipient culture has a crucial influence on all aspects of the translation process' (Kruger, 2010: 123). Toury (1995:54) explains the process of translation as follows:

Translation activities should rather be regarded as having cultural significance. Consequently, 'translatorship' amounts first and foremost to being able to play a social role, i.e., to fulfil a function allotted by a community - to the activity, its practitioners and/or their products - in a way which is deemed appropriate in its own terms of reference. The acquisition of a set of norms for determining the suitability of that kind of behaviour, and for manoeuvring between all the factors which may constrain it, is therefore a prerequisite for becoming a translator within a cultural environment.

Lathey (2006: 18) regards the translation of children's literature as being of a dual nature because it belongs to both the socio-educational system and the literary system. The text has to have literary merit as well as address the needs of the education system. Three concomitant issues relating to this are the function of the text, the cultural values of the text and the aesthetic 
merit of the text. One might want to examine some of the following options selected and summarised from a list of twelve proposed translation strategies (Newmark, 1988: 46-53):

- $\quad$ word-for-word translation

- literal translation

- faithful translation (meaning that the precise contextual meaning of the original is reproduced within the constraints of the target language grammatical structures)

- semantic translation (in which assonance, word-play or repetitions are created at the expense of the original meaning of the text)

- free translation (in which the content but not the style is reproduced, as in legal documents or explanatory texts)

- adaptation (in which the culture of the source language is converted to the culture of the target language). ${ }^{1}$

In considering options in methods of translation in other words, literal, word-for-word adaptation seems the most viable in order to keep the literary criteria in place and ensure maximum positive identification of the reader with the material. Boase-Beier and Holman (1998: 5) point out that a translation could be perceived to be 'wrong' when a reader finds that the text in the target language does not 'fit the image that the reader prefers to associate with the original text'. This point is debatable because one of the strongest arguments in favour of reading fiction at all is that it allows a person (child or adult) to experience the world through another person's eyes and to learn about other ways of seeing the world and other cultures. The danger of descending into cultural stereotypes when translating must also be addressed. While culture cannot be perfectly translated, the uncritical assumption that culture and language are completely intertwined is highly debatable - the Irish and Scots see themselves as a particular culture even though they have largely shifted from their original languages to English, and the speakers of Indian and Pakistani languages who have settled in South Africa now regard themselves as English mother tongue speakers whilst having retained their own distinctive cultures and religions.

The problem of cultural differences and the use of English as the language of instruction alluded to here is one which translators of children's literature in South Africa are going to face more and more frequently in future, taking into account that eleven official languages, the unofficial languages, immigrant languages, as well as a widening book market in Africa and abroad, are likely to appear in children's books in the future. This has been the case in the last ten years as a result of several waves of national curriculum renewal and revisions, which has introduced insecurity among publishing houses and their future relationships within educational markets, and has resulted in South African educational publishing having been in turmoil, and virtually frozen for long intervals. Given this scenario, it is likely that much translation from wellpublished to less published languages will have occurred and is likely to occur in the future.

With regard to translation, therefore, translated texts need to adhere to the literary and linguistic characteristics of literature for children, while at the same time facilitating acquisition of the target language, whether that be English or an African language as the language of learning and teaching. 
If one considers the translation of African language texts of children's literature into English, one is opening up a huge market and facilitating the insertion of African themes and styles into global English literatures. On a national level, the market would include, firstly, children studying through the medium of English as a medium of instruction and, secondly, all children in Africa who are learning to read through the medium of English. On an international level, it would include children in the English-speaking world; children who are learning English as a second language; and children who are exposed to English as a lingua franca. Translations which are adapted and which are less literal lead to more or at least equally delightful texts. As already mentioned, if young readers are not exposed to the indigenous cultures in the beginner reader phase (Bloch, 2006: 44), the motivation for reading may be lost for life. This argument is extended below, by highlighting the contribution 'authentic' literature and traditional folktales have to make to reading development.

\section{THE IMPORTANCE OF LITERARY CRITERIA}

Characteristics of good children's literature for beginner readers are universally recognised. Essential characteristics of children's literature world-wide include practice and repetition, association, selectivity, categorisation, pattern 1 learning (grammar as well as collocation), inferences, guessing, prediction and imaginary responses and the encouragement of questions (Oxford, 1995).

The choice of appropriate reading texts needs to be based on a number of criteria. In South Africa, the development phase the child, firstly is more relevant than the age of the child, as a result of economic factors which result in school entering and school leaving ages being widely disparate. Secondly, what children of different development phases want to read, or are perceived as needing to read, is an important consideration. The literature for children should create a positive learning climate; should connect with the syllabus as a whole (overtly and covertly); should improve the learner's reading ability and foster a feeling of success; should challenge common-sense and simplistic ideas about the world; should build vocabulary; and should help to develop life skills and general knowledge. Gamble and Yates (2008: 4) are major exponents of literature for literacy and feel that children should not be introduced into literacy by relying on what they call 'adult literacy events'. Critical literacy should also be encouraged from a young age in order to establish the future adult reader's literary competence.

In the Foundation Phase, literature should be suitable for holistic learning i.e. reading, listening, speaking and writing. It should have cross-curricular relevance and encourage lots of interaction and participation. According to Heald-Taylor (1987: 6) elements such as rhyme, rhythm, patterns, logical sequences and traditional story structures are essential. They add that books for the Foundation Phase should have little text, should incorporate repetition, predictability, pictures, be theme-based, have 'real' stories in 'real' language, and also have imaginative content. Locally, Van Reenen (2011: 23) argues in favour of picture books as the answer for second-language emergent readers, because the pictures provide prompting for meaning making and imaginative personal responses. This, in turn, renders the second-language text less impenetrable. 
How does one keep the essential elements of children's literature alive in translated versions, while simultaneously meeting the literacy criteria for Foundation Phase readers? If the objective is to nurture a love for and enjoyment of reading as a lifelong goal in children at a young age, then elements of predictability, surprise, repetition, and strong storylines rather than reading book lines, are essential:

Literature with many predictable features such as strong rhythm and rhyme, repeated patterns, refrains, logical sequences, supportive illustrations, and traditional story structures provide the emergent reader support in gaining meaning from the text. (HealdTaylor, 1987: 6).

The general perception is that 'plain' or 'simple language is required in order to reach children. When using plain language for clarity and precision in children's reading material, the whole notion of children's creative and interpretive faculties is easily overlooked. Literary elements such as musicality, sound play, 'exotic', 'funny' and 'different' words, which facilitate children getting interested in reading, are essential. Textbooks cannot fulfil this function and reading for pleasure and leisure is what makes the difference between stimulating a creative response to new ideas and simply 'consuming', duplicating and accepting what is on the page. The use of existing, familiar codes, in addition to the use of elaborations on existing codes, is what enhances literacy development. This would include adding repertoires which were previously unfamiliar to the child, and would result in expanding repertoires of expression and expanding the child's vocabulary (Lo Bianco, 2000: 92). Over and above these, some meta-skills such as being prompted to organise and evaluate one's learning, managing one's emotional responses, learning to compensate for gaps and missing knowledge, memory skills, and group learning, if built into the curriculum, can provide the development of these crucial reflexive skills in critical reading. In addition, children's reading needs to be transformative in that 'students are encouraged to view problems, themes, concerns and concepts from the perspective of different cultural groups'. (Rasinski \& Padak, 1990: 577). The following section explains what folktales have to offer in this regard.

\section{AFFECTIVE ENGAGEMENT, MULTILITERACIES, MOTIVATION AND AGENCY}

The additional but not less important consideration in teaching reading to beginner readers is to ensure high motivation. According to current social identity theory, as discussed by Burgess (2003: 160),

people strive to achieve, maintain and enhance a sense of positive social identity. As part of this effort they continually construct multifaceted personal, relational and social identities in a process that is influenced by personal, social, cultural and environmental forces.

This crafting results in a stable, but not fixed, sense of identity that influences behaviour in reasonably predictable ways. Young children are generally psychologically disposed by education and society to elicit positive and rewarding responses from surrounding adults, and 
will therefore copy, imitate and transform themselves towards an identity which is most rewarded.

Emotions play a central role in learning and language development (Greenspan \& Shanker, 2004: 210). Interest, attitude and self-image are the most distinguishable affective aspects of the reading process (Roe \& Smith 2011). In the event, however, that reading becomes a burdensome activity, children will avoid it and lose self-confidence, as there is no pleasure and no feeling of achievement involved. As Lenski (2008: 43) points out in her work on adolescents: 'The act of avoiding reading sets the stage for further reading failure, which can result in learned helplessness. Therefore they lose the motivation to try to read difficult texts.' This applies equally to beginner readers. Current literacy theory addresses the question of multimodalities as central to the language acquisition question, especially in multilingual countries. Literacy as such always refers to 'a system both of expression and recording in physical, material and permanent form the meanings expressed in the first semiotic systems in ways which are specific to the second semiotic system' (Kress, 2006:39). Consequently, the belief that 'plain' or 'simple' language is required in order to reach children is probably a myth worth examining. This would include adding repertoires which were previously unfamiliar to the child, and would result in expanding repertoires of expression and expanding the child's vocabulary (Lo Bianco, 2000: 92).

The child gains a voice by making meaning and empowers herself positively in providing access to new meanings and varied 'preferred' socially essential knowledge. Thus, the accommodation of varied learning styles, the consideration of multimodality and the facilitation of positive identification inextricably ties the role of literatures, and literatures in translation, to the development of literacy.

If a classroom, or any other learning context, allows children to express themselves more freely, then that space changes children. Children are likely to feel empowered with a new perspective towards the classroom and what it represents. Two Xhosa-speaking boys in a class of twenty Afrikaans children could easily feel excluded in verbal communication The use of visual media, for example, would allow these boys an opportunity to reveal potential capabilities, thereby promoting a positive identity. This demonstrates how multiliteracies can be used to steer and control the direction of learning to suit specific needs and thus allow each student the possibility of feeling successful in making strides towards deeper understandings and connections to fellow humans (De Haan \& Elbers, 2005: 330).

Teaching and learning strategies based on a multiliteracies approach promote respect for nonmainstream learners and their input and participation in classes where the language of learning and teaching is not their mother tongue or home-based language or dialect (Walsh \& Albright, 2006: 291; Archer, 2006: 451; Blommaert, Collins \& Slembrouck, 2005: 198). Multiliteracies present an opportunity to portray one's culture without hindrance from the dominant culture, an accordance that has not been so available previously in the South African context, for example. We argue that children's literature has an invaluable contribution to make to expand multimodal language learning opportunities through song, performance and art work. Children learn best through guided participation in an interactive relationship with role models (Rogoff, 1990: 7). This theory has been put into practice and has been proven highly successful in local research on the Vulindlela Reading Clubs in South African township areas (Musthan, Guzula \& Mahobe, 
2011:,4). Children's book authors and illustrators are invited to interact with the book club members, thereby inspiring them to identify with real authors and illustrators, in order to learn to conceive of themselves as authors and illustrators of their own texts.

Multimodal curricula enable powerful global repertoires to be recontexualised on the periphery, while at the same time allowing mainstream economic communities to access information on and about the periphery. Detraditionalisation of discourses then runs concurrently with increased interaction with dominant discourses, which benefits all learners. The development of agency is influenced by the tools to which one has access, as well as to by one's surroundings (Hull \& Katz, 2006: 47). A positive outcome of the support for this enhances a sense of agency and has far-reaching implications for the curriculum responsiveness of learners. What is conceived of as appropriate learning space and material therefore needs to remain within the possibility of localised identification. This is particularly pertinent to South Africa, where the multilingual class room, often with an additional language as language of learning and teaching, could inadvertently alienate learners.

The possibility of children being disadvantaged because of their background, linguistically or otherwise, is a reality in education. It is in this situation that teachers have to be aware of students' different backgrounds and facilitate equitable participation, (Hull \& Zacher, 2004: 3). Empowerment and growth in a student's agentive self are only possible if teachers respect all students and institute ways of dealing with multilingualism. Multimodal learning opportunities may be an answer in providing some success in this quest.

\section{FOLKTALES AS AUTHENTIC LITERATURE}

Folktales provide a valuable source of reading material for the beginner reader. South African children's literature relating to local content, genre and themes, and which is culture-specific and perhaps linguistically parochial, may be seen not to suit a foreign readership. While it is a purely editorial market-related decision as to how far to adapt texts in order to increase marketability, we would argue for localised choices to be expanded in order to be more inclusive at the local level, while at the same time tapping into universal commonalities of what appeals to children, and which instils ethical ecologically-based awareness (Barton, 2007) and self-reflexivity.

The folktale is also universal and an eternally first choice for introducing children to stories, and common themes occur across cultures. Sky-McIlvain (2009) explains that fairy tales, fables and myths have intrinsic value as $U r$-tales, tales on which much of Western literature is based, and that recognising the oldest character archetypes, settings, and story patterns in current works enriches the reading experience. The inclusion of folktales from around the world is a prerequisite for the sociological and psychological development of the child. It also provides a set of mental puzzles to be solved - a reader's search that simulates deeper reading. Making connections is itself a higher-order thinking skill that students sorely need to develop. This is particularly the case in schools in South Africa where recall and rote learning methods are being perpetuated due to teacher's desperate attempts to control overcrowded classes.

Bettelheim (1997: 6), in his seminal work on the importance of the role of stories in the development of the imagination, states that the fairy tales/folktales constitute a means of 'dealing 
with universal human problems, particularly those which preoccupy the child's mind; these stories speak to his budding ego and encourage its development'. Furthermore, he says that folktales are the means for a child to develop coping mechanisms for situations in which they find themselves. Folktales allow children to develop psychosocial skills because they expose children to situations and offer solutions within the narrative. Because folktales are multidimensional and multi-layered in terms of interpretive value, they can be read and enjoyed and related to across age and cultural groups.

For instance, The Ugly Duckling (an ancient European folktale) and Fly, Eagle Fly (an African folktale) share the same theme, i.e. acceptance of difference; pride in who you are; prejudices and the universal theme of ingrained negative labelling of outsider groups and individual difference; and in-group identification and conformity conceived of as positive. Most recently, well-known traditional European folktakes such as Pinocchio and The Ugly Duckling have appeared in adapted format for African readers, with African-based cultural and landscape illustrations and have been taken up in the book market with great excitement from publishers and book buying parents and teachers, organisations and publishing houses which are doing their utmost to promote reading in multilingual formal learning contexts in South Africa, e.g. Vulindlela Reading Clubs, PRAESA at UCT and Oxford University Press. Unfortunately, the prescriptions for school-based reading material are increasingly less flexible, which makes the distribution of authentic literature for literacy increasingly difficult.

\section{CONCLUSION}

To sum up then, transformative literature, i.e. literature which potentially nurtures a strong form of agency in the child, may be defined as that which provides pleasure, that which echoes the interests of the child, and allows the child to be able to imagine living in another time and place, and in another's shoes (Mitchell, 2003:306). As Wragg, Haynes and Chamberlin (1998:28) say, reading is the active construction of meaning, rather than the simple reconstruction or comprehension of the author's own meaning. This means that the child gains a voice by making meaning and by being able to access new meanings and varied 'preferred' socially essential knowledge through exercising independent choices. Thus, the consideration of multi-modal access and creative interpretation, and the facilitation of positive identification, inextricably ties the role of literatures, and literatures in translation, to literacy and intellectual development.

\section{ENDNOTES}

${ }^{1}$ The translation of children's poetry is the focus of another article in which specific examples will be analysed and discussed.

\section{REFERENCES}

ARCHER, A. 2006. Multimodal approach to academic literacies: Problematising the visual/verbal divide. Language and Education, 20(6):449-462.

BAKER, M. 2011 (1992). In other words: A coursebook on translation. London: Routledge. 
BARTON, D. 2007. Literacy: An introduction to the ecology of written language. Oxford: Basil Blackwell.

BETTELHEIM, B. 1977. The uses of enchantment. The meaning and importance of fairy tales. New York. Vintage Books

BLOCH, C. 2006. Theory and strategy of early literacy in contemporary Africa - with special reference to South Africa. Cape Town: PRAESA (UCT) Occasional papers.

BLOMMAERT, J, J COLLINS \& S SLEMBROUCK. 2005. Spaces of multilingualism. Language and Communication, 25:197-216.

BOASE-BEIER, J \& M HOLMAN. 1999. The practices of literary translation. Manchester: St Jerome.

BRUNER, J. 1994. The remembered self. In Neisser, U \& R Fivush (eds), The remembering self: Construction and agency in self-narrative. Cambridge, UK: Cambridge University Press.

BROWN, KJ. (1999). What kind of text: For whom and when? Textual scaffolding for beginner readers. The Reading Teacher, 53(4):292-307

BURGESS, SM. 2003. Within-country diversity; is it the key to South Africa's prosperity in the changing world? International Journal of Advertising, (22):157-182.

DE HAAN, M \& E ELBERS. 2005. Reshaping diversity in a local classroom: Communication and identity issues in multicultural schools in the Netherlands. Language and Communication, 25:315-333.

GAMBLE, N \& S YATES. 2008. Exploring children's literature. $2^{\text {nd }}$ edition. London: Sage.

FAIRCLOUGH, N. 1989. Language and Power. London: Longman.

GREENSPAN, S \& SG Shanker. 2004. The first idea. How symbols, language and intelligence evolved from our primate ancestors to modern humans. Cambridge Mass: De Capo.

HALLIDAY, MAK. 1996. Literacy and linguistics: A functional perspective. In Hasan R \& G Williams, Literacy in society. 339-376.

HEALD-TAYLOR, G. 1987. Predictable literature selections and activities for language arts instruction. The Reading Teacher, 41(1):6-12.

HUCK, CS. 1992. Literature and Literacy. Language Arts, (69):520-525.

HULL, GA \& M KATZ. 2006. Crafting an agentive self; Case studies of digital storytelling. Research in the Teaching of English, 41(1):43-79.

HULL, GA \& J ZACHER. 2004. What is alter-school worth? Developing literacies and identities out-of-school. Voices in Urban Education, 3:36-44.

KRESS, G. and VAN LEEUWEN. 2006. Reading Images ( $2^{\text {nd }}$ edn). London:Routledge.

KRUGER, H. 2010. The translation of children's literature in the South African educational context. $\mathrm{PhD}$ Thesis. Wits University.

LAKOFF, G \& M JOHNSON. 1980. Metaphors we live by. Illinois: University of Chicago Press. 
LATHEY, G. (ed). 2006. The translation of children's literature. A reader. Multilingual Matters.

LENSKI, S. 2008. Struggling adolescent readers. Problems and possibilities. In Lenski, S \& J Lewis (eds), Reading success for struggling adolescent learners. New York: The Guilford Press.

LO BIANCO, J. 2000. Multiliteracies and Multilingualism. In Cope, B \& M Kalantzis (eds), Multiliteracies: Literacy, learning and the design of social futures. London: Routledge. 92105.

MARTINEZ, MG \& LM McGEE, LM. 2000. Children's literature and reading instruction: Past, present and future. Reading Research Quarterly, 35(1):154-169.

MEGRAB, RA. 1998. Ideological shifts in cross-cultural translation. In Boase-Beier, J \& M Holman (eds), The practices of literary translation. Brooklands, Manchester: St Jerome. 59-70.

MUSTHAN, N, X GUZULA \& N MAHOBE. 2011. 'Vulindlela Reading Clubs - Building literate communities'. Presentation at the Practitioners Conference: Implementing Multilingual Practice, Eastern Cape Economic Consultative Council (ECECC), Regents Hotel, East London. 29-30 Sept.

NEWMARK, P.1988. A textbook of translation. New York: Prentice Hall.

OXFORD, RL. 1995. Language learning strategies: What every teacher should know. New York: Newbury House.

RASINSKI, TV \& ND PADAK. 1990. Multicultural learning through children's literature. Language Arts, 67, October:576-580.

ROE, B.D. \& S.H. ROSS. 2011. Teaching reading in today's elementary schools. $7^{\text {th }}$ edition. New York: Houghton Mifflin Harcourt.

ROGOFF, B. 1990. Apprenticeship in thinking: Cognitive development in social context. NY: Oxford University Press.

SKY-McILVAIN, E. 2009. The uses of fairy tales. Literacy Journal [Online]. Available: http://eskymaclj.blogspot.com/2009/07/uses-of-fairy-tales.html. [2011, July 6].

STAN, S. 2004. Rose Blanche in Translation? Children's Literature in Education, 35(1):21-33.

STEIN, P. 2001. Classrooms as sites of textual, cultural and linguistic reappropriation. Comber, B \& A Simpson (eds), Negotiating critical literacies in classrooms. Mahwah, New Jersey: Lawrence Erlbaum. 151-169.

TOURY, G. 1995. Descriptive translation studies and beyond. Amsterdam and Philadelphia: John Benjamins.

VAN REENEN, C. 2011. Having their say: Engaging with contemporary picture books at work and at play. Journal of Literary Studies, 27(2) July:1-25.

WALSH, C \& J ALBRIGHT. 2006. Re-envisioning teacher education in the new media age: Multiliteracies, multimodality and internet communication technologies. Proceedings of the 2006 Australian Teacher Education 


\section{WRAGG, EC, CM WRAGG, GS HAYNES \& C CHAMBERLIN 1998. Improving Literacy in the Primary School. London: Routledge.}

\section{BIOGRAPHICAL NOTES}

Liesel Hibbert is currently Professor in the Department of Applied Language Studies at Nelson Mandela Metropolitan University in Port Elizabeth. Her PhD work at the University of Cape Town was on political rhetoric in South Africa. She has spent many years in teacher training, has taught Academic Literacy, South African Writing, Business Communication and Research Methods for Master's students in the Management Sciences. Her current work with graduate student examines notions of literacy in a global world, focusing on ethnographic case studies in local economically marginalized communities. One of her most recent publications related to the above issue, is 'Local and global perspectives on overcoming literacy challenges in South Africa' which appeared in the International Journal of the Sociology of Language in 2010.

Marius Crous lectures in the Department of Language and Literature at NMMU. His interests are Afrikaans literature, creative writing and translation studies. His third volume of poetry is due in 2012. $\mathrm{He}$ is also a regular reviewer of books in magazines and newspapers. 